\title{
Juvenile myoclonic epilepsy mimicking focal epilepsy
}

\author{
Epilepsia mioclônica juvenil imitando epilepsia focal \\ Rubia Rasseli Sfalsini', Elida Bassetti', José Furtado Alves Junior', Valmir Passarelli² \\ ${ }^{1}$ Neurology Resident at Santa Marcelina Hospital, São Paulo SP, Brazil; \\ ${ }^{2}$ Neurologist at Santa Marcelina Hospital, São Paulo SP, Brazil. \\ Correspondence: Valmir Passarelli; Rua Oscar Freire 1.380 / apto. 51; 05409-010 São Paulo SP - Brasil; E-mail:valmirpas@ig.com.br \\ Conflict of interest: There is no conflict of interest to declare. \\ Received 15 January 2012; Received in final form 27 April 2012; Accepted 07 May 2012
}

Three cases of juvenile myoclonic epilepsy (JME) mimicking focal epilepsy are here presented.

\section{CASE 1}

A 16-year-old male began to have sudden shaking episodes in his right upper limb, when he was 14 years-old. Such episodes were referred to as scares and occurred predominantly in the mornings. After a few months, he had a generalized tonic-clonic seizure (GTCS). An electroencephalogram (EEG), performed after sleep deprivation, was unremarkable. Phenobarbital (PB) was administered, which resulted in partial control of the seizures. He was referred to our clinic with the hypothesis of partial epilepsy. After replacing PB with valproic acid (VPA), for a year he had no further seizures.

\section{CASE 2}

A 33-year-old woman started having GTCS at the age of 11 years, during her waking hours, predominantly in the mornings. After a few months of similar episodes, an EEG was performed, which showed generalized epileptiform discharges, predominantly in the anterior regions. Treatment consisting of PB and carbamazepine (CBZ) was administered, resulting in partial control of the GTCS (three to four months without seizures). However, sudden jerks of the limbs started to occur, predominantly in the right upper limb. These events occurred daily, especially on awakening. Another EEG was performed (Fig 1), and she was referred to our clinic with refractory focal epilepsy. After clinical evaluation, CBZ and PB were replaced with VPA, resulting in seizure control (for three years).

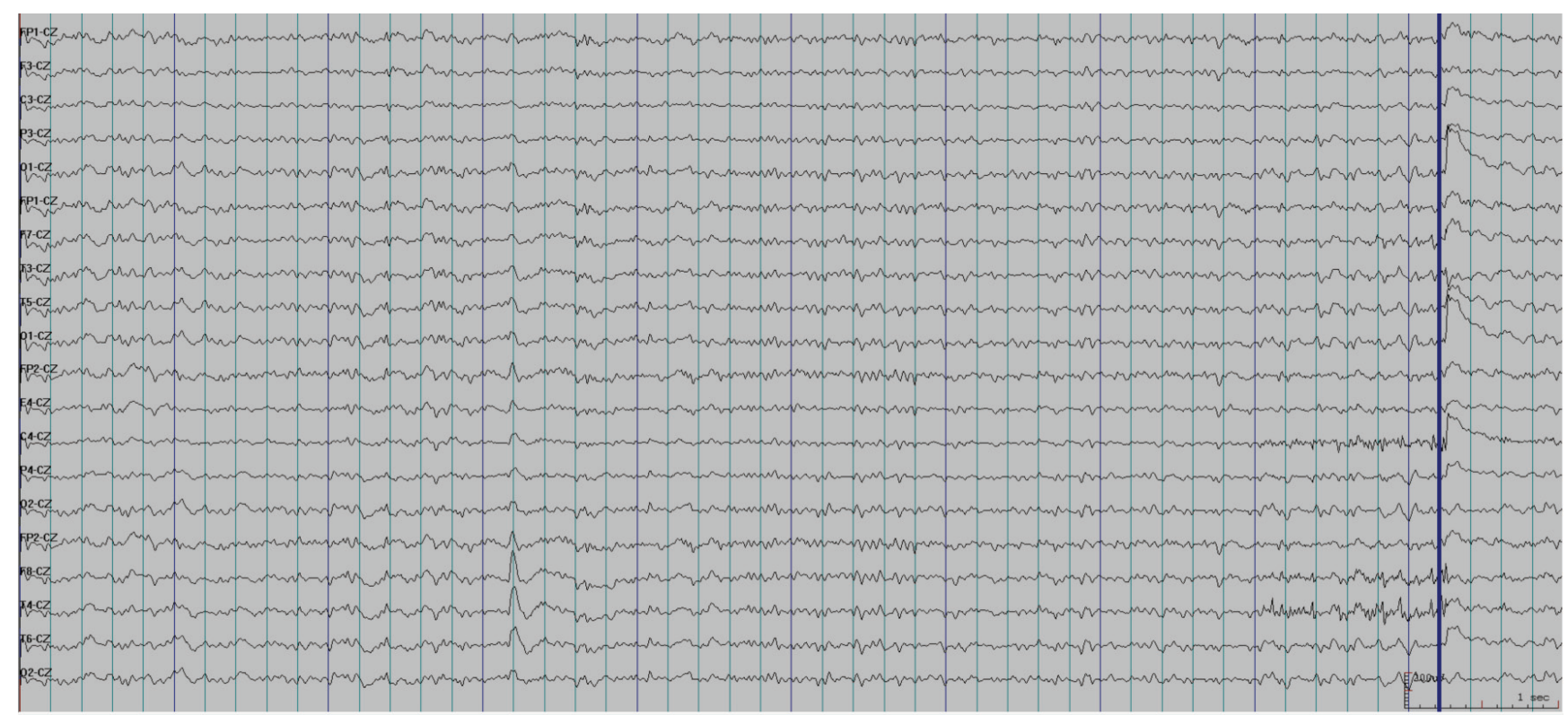

Fig 1. Electroencephalogram tracing showing slow-wave discharges of heightened aspect of projection in the right temporal region. 


\section{CASE 3}

A 36-year-old woman started, at the age of 18, to have episodes of sudden loss of consciousness, right cephalic version, and tremors in all four limbs, which lasted from two to three minutes. CBZ was administered, resulting in increased seizure frequency and new seizure patterns: sudden short jerks of the upper limbs, which happened daily at no specific time. An EEG showed generalized epileptiform discharges. CBZ was then replaced with VPA, and no further seizures occurred over a three-year period.

\section{DISCUSSION}

JME is an idiopathic generalized epilepsy syndrome, which usually begins at puberty. It is characterized by predominance of myoclonic seizures, often associated with GTCS and/or absence of seizures. The excellent response to valproic acid is well-known, however topiramate, lamotrigine, and levetiracetam are also effective. Lack of knowledge of focal clinical and/or electrographic manifestations favors erroneous diagnoses of focal epilepsy, thereby leading to ineffective treatments, particularly use of carbamazepine, oxcarbazepine and phenytoin, which may even worsen the seizure frequency and should be avoided when treating JME ${ }^{1}$.

Myoclonic seizures are brief muscle contractions, similar to shocks or scares. In JME cases, they are generally bilateral and symmetrical. Misinterpretation of myoclonic seizures and focal motor clonic seizure symptoms is common, and the main reason for this is the widespread lack of knowledge about the fact that myoclonic seizures in JME cases may be focal or asymmetrical ${ }^{2,3}$.

The idea that generalized epilepsy is associated with generalized electroencephalographic abnormalities is, at least, imperfect. Recent studies have suggested that focal EEG abnormalities are common in JME ( from 20 to $50 \%$ of the cases). Focal findings in JME cases include: outbreaks of focal slow waves that are independent of generalized epileptiform discharges (GED); independent focal epileptiform discharges, or preceding GED; and asymmetries or focal accents of GED (Fig 2) 2,3.

Cephalic version as the initial ictal event is considered to be an indication of focal seizure. In 1984, Ochs et al. reported cases of idiopathic generalized epilepsy (IGE) that had seizures with ictal cephalic version as the initial manifestation. Subsequently, several other studies have strengthened the possibility that versive seizures may be a manifestation of IGE, including JME $\mathrm{JM}^{3,4}$.

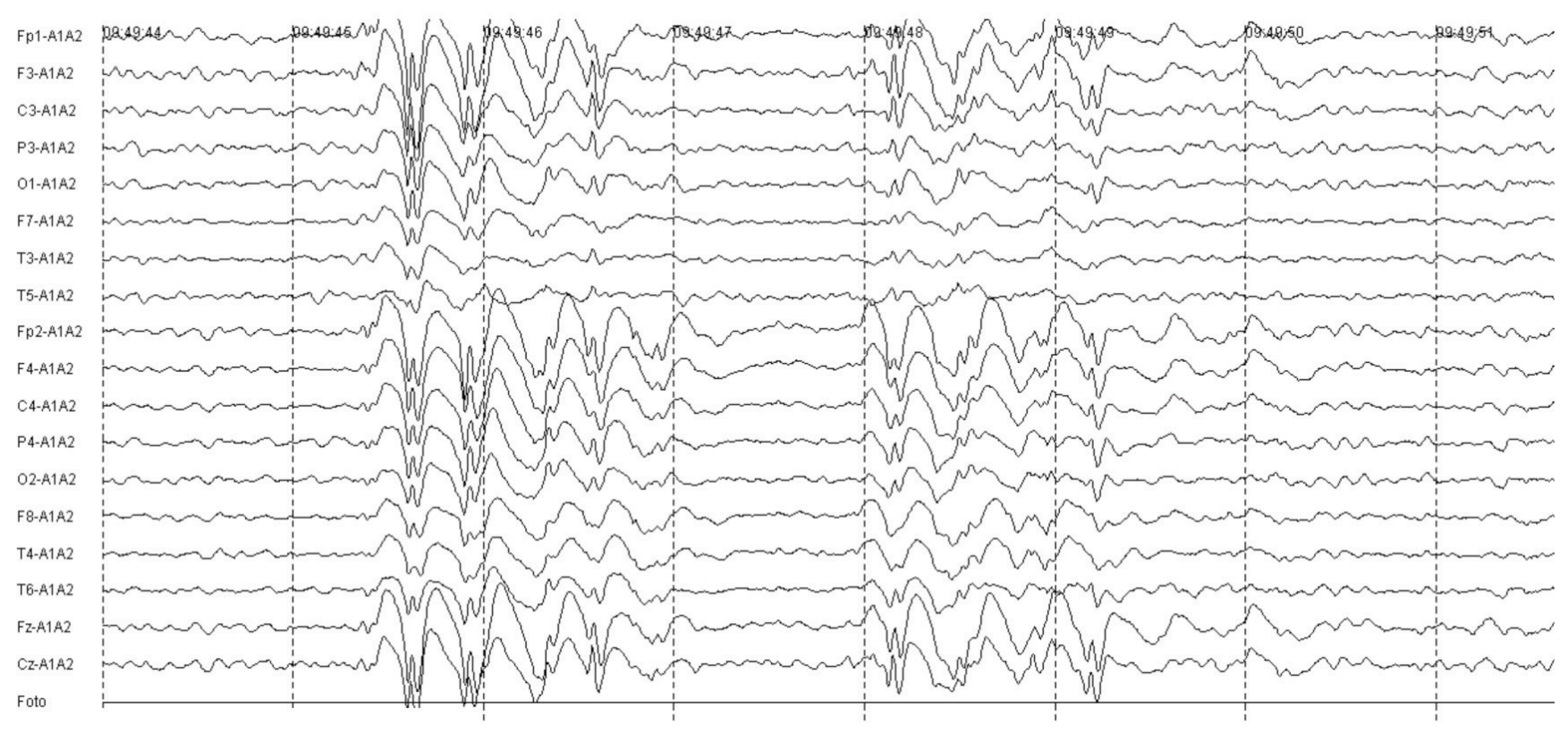

Fig 2. Electroencephalogram showing epileptiform discharges with generalized projection predominantly in the anterior regions.

\section{References}

1. Alfradique I, Vasconcelos MM. Juvenile myoclonic epilepsy. Arq Neuropsiquiatr 2007;65:1266-1271.

2. Ferrie CD. Idiopathic generalized epilepsies imitating focal epilepsies. Epilepsia 2005;46:S91-S95.

3. Montalenti E, Imperiale D, Rovera A, Bergamasco B, Benna P. Clinical features, EEG findings and diagnostic pitfalls in juvenile myoclonic epilepsy: a series of 63 patients. J Neurol Sci 2001;184:65-70.

4. Ochs R, Gloor P, Quesney F, et al. Does head-turning during a seizure have lateralizing or localizing significance? Neurology 1984;34: 884-890. 